Research Article

\title{
The Hydration and Compressive Strength of Cement Mortar Prepared by Calcium Acetate Solution
}

\author{
Ke Cao $\mathbb{D}^{1},{ }^{1}$ Liang Wang $\mathbb{D}^{1,2}$ Ying Xu $\mathbb{D}^{1},{ }^{1}$ Wenfeng Shen $\mathbb{D}^{1},{ }^{1}$ and Hao Wang ${ }^{1}{ }^{1}$ \\ ${ }^{1}$ School of Civil Engineering and Architecture, Anhui University of Science and Technology, Huainan 232001, China \\ ${ }^{2}$ Huaibei Mining Co., Ltd., Huaibei, Anhui 235000, China \\ Correspondence should be addressed to Liang Wang; 824894000@qq.com
}

Received 3 September 2020; Revised 9 March 2021; Accepted 11 March 2021; Published 28 March 2021

Academic Editor: Valeria Vignali

Copyright $(0) 2021 \mathrm{Ke}$ Cao et al. This is an open access article distributed under the Creative Commons Attribution License, which permits unrestricted use, distribution, and reproduction in any medium, provided the original work is properly cited.

Calcium acetate is the major component of the waste solution produced in treating recycled concrete aggregate (RCA) with acetic acid. Thus, the current work aims to explore the influence of calcium acetate solution on the performance of ordinary Portland cement. For this purpose, cement pastes and mortars were prepared using different concentrations, namely, 1, 2, and 3\%, of calcium acetate solution. The heat evolution results confirmed that the calcium acetate solution at a concentration of $2 \%$ could accelerate the hydration of the cement. The XRD/TGA results and SEM images also indicated that more ettringite and calcium hydroxide $(\mathrm{CH})$ are produced in the mortars prepared by the $2 \%$ calcium acetate solution. Moreover, the mortar containing the $2 \%$ calcium acetate solution has a denser microstructure than the control group according to the MIP tests results, and mortars cured for 3 and 28 days have a respective compressive strength, 23.34 and $15.43 \%$, higher than the control group. The finding of this research could also contribute to studying the effect of adding metal ions to weakly acidic solutions as mixing liquids on the performance of cementitious materials.

\section{Introduction}

As a building material, concrete is widely used all over the world, which has greatly improved the quality of human life. Meanwhile, it has consumed a lot of natural resources like sand and breakstone. From 2007 to 2014, the production of global aggregate had increased from 21 billion tonnes to 40 billion tonnes. Freedonia Group released a report saying that the global aggregate demand reached 51.7 billion metric tonnes in 2019 , with a yearly growth rate of approximately $5.2 \%$. It is also indicated in the report that the Asia-Pacific region had the highest demand for aggregate in 2019, with China accounting for more than half of the global demand [1]. However, in the past 30 years, China's construction industry has developed rapidly, and overdevelopment has gradually exhausted natural resources. China's sandstone market report also confirms the depletion of nearly half of China's inland natural sandstone resources [2].

In the meantime, behind the booming construction industry, we have produced a considerable amount of construction and demolition (C\&D) waste. In many countries, the proportion of C\&D waste is larger than any other solid waste stream [3]. For example, Japan, America, and European countries produce approximately 900 million tonnes of C\&D waste annually [4], and in Australia, the number is 7.5 million tonnes [5]. China, as the biggest producer of $C \& D$ waste globally, has also generated nearly 2 billion tonnes of C\&D waste in 2017 [6]. Therefore, to recycle C\&D waste has a significant impact on the environmentally sustainable development of many countries.

However, produced from C\&D waste, recycled concrete aggregate (RCA) has a poorer quality than natural aggregate (NA) due to the old mortar layer, which is attached to the RCA surface. The porosity of the mortar layer results in some negative properties of RCA, such as higher hygroscopicity, decreased strength, and greater crushing value. Accordingly, in comparison to the concrete containing NA, the higher creep and shrinkage and the lower workability of the concrete made with RCA have limited the practical applications of the RCA-concrete [7-9]. 
To improve the quality of RCA, some methods, including strengthening or removal of the attached mortar layer, have been proposed. The basic idea of the reinforcement of the mortar layer is filling the mortar's micro holes on the RCA surface. According to Shi et al., developing a strong interfacial transition zone (ITZ) between cement paste and RCA by filling the weak areas of the attached mortar is the primary goal of any strengthening treatment [10]. In this context, several methods using (a) pozzolana slurry [11], (b) polymer emulsion [12], (c) biodeposition of lime carbonate [13], and (d) carbonation [14] have been reported for treating RCA through strengthening the attached mortar. The attached mortar layer can be removed by means of a thermal or chemical process. In the thermal process, recycled concrete aggregate is first heated by a high temperature to weaken the attached mortar, and then the mortar layer can be removed by mechanical lapping. However, this method has two disadvantages: it consumes too much thermal energy and releases excess carbon dioxide [15]. On the other hand, the chemical process employs different types of acids such as sulfuric acid, phosphoric acid, hydrochloric acid, etc., rather than heating to weaken the attached mortar layer. For this purpose, RCA is immersed in an acid solution to remove some loose and cracked mortar, thereby reducing the hygroscopicity of RCA. The mechanical nature of the concrete containing the acid-treated RCA can be significantly enhanced. Nevertheless, strong acids used in this process not only threat the workers' health, but also add damaging ions to the RCA, which may cause durability problems in the concrete made from the acid-treated recycled concrete aggregate. Therefore, extra water must be used to clean the acid-treated RCA from the damaging ions. However, the wastewater can pose new environmental problems [16, 17]. Wang et al. [18] devised a green approach exploiting acetic acid to enhance the performance of RCA. Compared with the acids mentioned above, acetic acid enjoys considerable advantages such as economical, safe in operation, and clean in process. Their process can also enhance the compressive strength of the concrete formed by the waste solution from the treatment of RCA with acetic acid. Nonetheless, it is necessary to clarify the influences of the waste solution on the performance of the cement mortars.

The influences of $\mathrm{pH}$ of the mixing liquid on the performance of cementing materials have been studied in recent years [19-21]. Çomak [22] demonstrated that alkaline water whose $\mathrm{pH}$ value is lower than 13 improves the compressive strength and workability of cement mortar. Arunakanthi et al. [23] presented that the compressive strength of concrete prepared by the mixing water whose $\mathrm{pH}$ value is lower than 5.5 is much lower compared to the reference concrete. Based on the above researches, it is normally believed that the properties of concrete/mortar can be decreased when the used mixing water has a $\mathrm{pH}$ lower than 5.5 and can be improved while the $\mathrm{pH}$ is in the range of 10 to 12 . However, the influence of weakly acidic mixing liquids with a $\mathrm{pH}$ value in the range of 5.5 to 7.0 on the properties of cementing materials is not well addressed.
Except for the $\mathrm{pH}$ value, the properties of the cementitious materials are also controlled by the ionic composition of the mixing water [24]. In [18], calcium and acetate ions are the major components of the waste solutions from the treatment of RCA with acetic acid. In this article, the quality of RCA can be significantly improved by soaking in acetic acid solution with mass concentration no more than $3 \%$. When the waste solution of the treatment was used as admixture for new concrete, the compressive strength of concrete was increased by $14 \%$ compared with the one with fresh water, indicating that the calcium acetate probably improves the strength of concrete. The concentration of calcium ion was $7.27 \%$ for waste solution generated after treating the RCA with 3\% acetic acid, suggesting that the 3\% (7.59\% of calcium ion in solution) concentration was enough for the concrete. Therefore, $1 \%, 2 \%$, and $3 \%$ concentrations of calcium acetate solutions were used in this study to investigate the effect of concentration of calcium acetate solution on hydration and compressive strength of cement mortar. Also, the heat evolution tests, XRD/TGA analyses, SEM images, and MIP tests were employed to assess the effect of the concentration of calcium acetate solution on the nature of the formed cement pastes and mortars.

\section{Experimental Procedures}

2.1. Materials. A Huainan-based company in China provided the ordinary Portland cement (OPC). Table 1 shows its chemical composition based on X-ray fluorescence (XRF) analysis. In the experiments, we used the natural river sand as the fine aggregate, which had a fineness modulus of 2.56 from Huaihe River. The calcium acetate reagent, i.e., $\mathrm{Ca}\left(\mathrm{CH}_{3} \mathrm{COO}\right)_{2}$, was supplied by local suppliers.

\subsection{Methods}

2.2.1. Mortar Preparation. The calcium acetate reagent was dissolved in water to prepare solutions with different concentrations, namely, 1, 2, and 3\%. We cast four groups of mortar samples, i.e., a control group with no calcium acetate regent and three groups containing various concentrations of the calcium acetate reagent. The different samples were named CA0 (control), CA1 (1\% calcium acetate), CA2 (2\% calcium acetate), and CA3 (3\% calcium acetate). The mix design of the mortar samples is tabulated in Table 2.

2.2.2. Heat Evolution Analysis. For testing the heat of hydration, cement and water or solution $(30 \mathrm{~g}$ and $15 \mathrm{~g}$, respectively) were used as the mixing liquid to prepare each cement paste sample, i.e., a liquid-to-cement mass ratio of 0.5 , in a plastic cup under a constant temperature of $20^{\circ} \mathrm{C}$. The mixture was manually stirred for 60 seconds and then poured into a plastic ampule. We put the ampule into an isothermal calorimeter to test heat flow and hydration heat for 72 hours. 
TABle 1: Chemical composition of the OPC.

\begin{tabular}{lcccccccc}
\hline Composition & $\mathrm{CaO}$ & $\mathrm{SiO}_{2}$ & $\mathrm{Fe}_{2} \mathrm{O}_{3}$ & $\mathrm{Al}_{2} \mathrm{O}_{3}$ & $\mathrm{SO}_{3}$ & $\mathrm{MgO}$ & $\mathrm{K}_{2} \mathrm{O}$ & Others \\
\hline Percentage & 63.21 & 21.30 & 4.92 & 4.87 & 2.03 & 1.21 & 0.69 & 0.82 \\
\hline
\end{tabular}

TABle 2: Mix design of mortars.

\begin{tabular}{lccc}
\hline Components & Water or solution & Cement & \\
\hline Proportion $\left(\mathrm{kg} / \mathrm{m}^{3}\right)$ & 275 & 548 & Sand \\
\hline
\end{tabular}

2.2.3. Hydration Product Examination. The thermogravimetric analysis (TGA) of groups, namely, CA0, CA2, and $\mathrm{CA} 3$, was conducted at a heating rate of $10^{\circ} \mathrm{C}$ per min from 30 to $800^{\circ} \mathrm{C}$ under an $\mathrm{N}_{2}$ flow $(30 \mathrm{~mL}$ per min) to avoid carbonation. The samples were immersed in isopropanol for seven days to stop hydration, which were then powdered and subjected to vacuum drying for two days; it should be noted that the solvent was exchanged twice during the first $24 \mathrm{~h}$. To prevent carbonation, a pure alumina crucible was used as the container for fifty milligrams of the powdered sample, which was covered with a lid made of aluminum. Then, the weight loss in a temperature range of $400-500^{\circ} \mathrm{C}$ can be used to measure the calcium hydroxide content, which is mainly caused by the dehydration of calcium hydroxide, and that in a temperature range of $700-800^{\circ} \mathrm{C}$ is resulted from the $\mathrm{CaCO}_{3}$ decomposition produced by the carbonation of calcium hydroxide [25-27]. The related chemical reactions are expressed as follows:

$$
\begin{gathered}
\mathrm{Ca}(\mathrm{OH})_{2} \longrightarrow \mathrm{CaO}+\mathrm{H}_{2} \mathrm{O} \\
\mathrm{CaCO}_{3} \longrightarrow \mathrm{CaO}+\mathrm{CO}_{2}
\end{gathered}
$$

Accordingly, the calcium hydroxide content is calculated as follows:

$$
\mathrm{M}_{\mathrm{Ca}(\mathrm{OH})_{2}}=\frac{74}{18} \mathrm{M}_{\mathrm{H}_{2} \mathrm{O}}+\frac{74}{44} \mathrm{M}_{\mathrm{CO}_{2}}
$$

where $\mathrm{M}_{\mathrm{Ca}(\mathrm{OH})_{2}}$ is the $\mathrm{CH}$ content and $\mathrm{M}_{\mathrm{H}_{2} \mathrm{O}}$ stands for the weight loss from 400 to $500^{\circ} \mathrm{C}$ and $\mathrm{M}_{\mathrm{CO}_{2}}$ represents the weight loss in a temperature range of $700-800^{\circ} \mathrm{C}$.

$\mathrm{X}$-ray diffraction (XRD) analysis of groups CA0, CA2, and CA3 was carried out to determine the mineralogy of the precipitates produced by the proposed treatment.

Further scanning electron microscope (SEM) was used to directly observe the formation of mineral precipitates in mortars.

2.2.4. Workability. According to ASTM C1437 [28] and GB/ T 1346-2011 [29], the flowability and setting time of mortars were measured, respectively. These two properties can evaluate the workability of mortars.

2.2.5. Compressive Strength Analysis. Based on ASTM C109 [30], we cast the mortars into specimens (dimensions, $50 \mathrm{~mm} \times 50 \mathrm{~mm} \times 50 \mathrm{~mm}$ ) using plastic molds. Afterward, they were cured in normal conditions at $23^{\circ} \mathrm{C}$ and $a>95 \%$ relative humidity. The measurements were taken after curing the samples for 3,7 , and 28 days.

2.2.6. Mercury Intrusion Porosimetry (MIP) Test. After the $28 \mathrm{~d}$ compressive strength tests, Mercury Intrusion Porosimetry (MIP) tests were conducted on the samples to determine the pore structure properties of the mortars.

\section{Results and Discussion}

3.1. Evolution of Hydration Heat. The heat flow and hydration heat of the cement paste samples at different concentrations of calcium acetate are presented in Figures 1(a) and 1(b). The heat flow variation of CA2 in Figure 1(a) shows that the cement paste containing $2 \%$ calcium acetate exhibits a higher and stronger peak of tricalcium silicate $\left(\mathrm{C}_{3} \mathrm{~S}\right)$ hydration compared to the other groups and the paste containing 3\% calcium acetate demonstrates a higher and stronger peak of tricalcium aluminate $\left(\mathrm{C}_{3} \mathrm{~A}\right)$ hydration compared to the other groups, which is mainly attributed to the high content of calcium ions in the solution. In fact, the additional calcium ions at an appropriate concentration accelerate the formation of $\mathrm{C}_{3} \mathrm{~S}$ and $\mathrm{C}_{3} \mathrm{~A}$. According to Figure 1(b), the calcium acetate at concentrations of 2 and $3 \%$ increase the hydration heat, indicating that the calcium acetate, within a certain range of concentrations, could stimulate the hydration of cement.

3.2. Hydration Products. We conducted the XRD analyses to examine the impact of various concentrations of calcium acetate on the cement hydration products. The XRD patterns in Figure 2(a) demonstrate that the addition of calcium acetate could slightly increase the content of ettringite and portlandite in the samples after three days of curing. Similar trends are also observed in Figure 2(b), which describes the hydration products of the cement cured for 28 days. It should be indicated that since an exact quantitative analysis of the hydration products cannot be made based on these XRD patterns, the TGA analysis of the cement pastes was also made.

On each sample's derivative weight loss diagram, there are four main peaks concerning the decomposition of ettringite, alumina ferric oxide monosulfate (AFm), portlandite, and calcite. As can be seen, their normal decomposition temperature is in the range of $80-120^{\circ} \mathrm{C}, 180-200^{\circ} \mathrm{C}$, $400-500^{\circ} \mathrm{C}$, and $700-800^{\circ} \mathrm{C}$, respectively [31-34]. According to the abovementioned temperature range and the method 


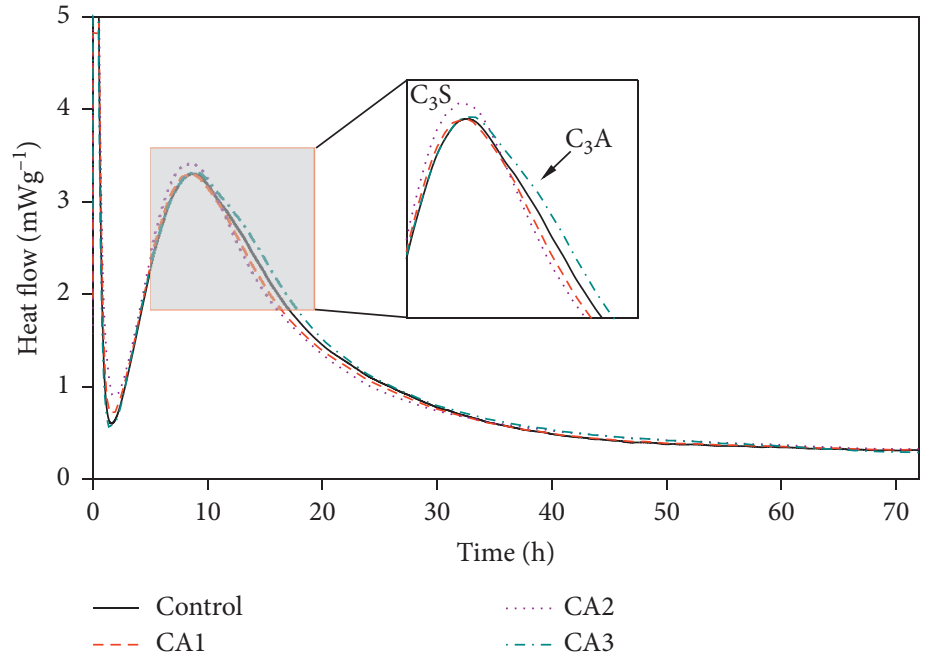

(a)

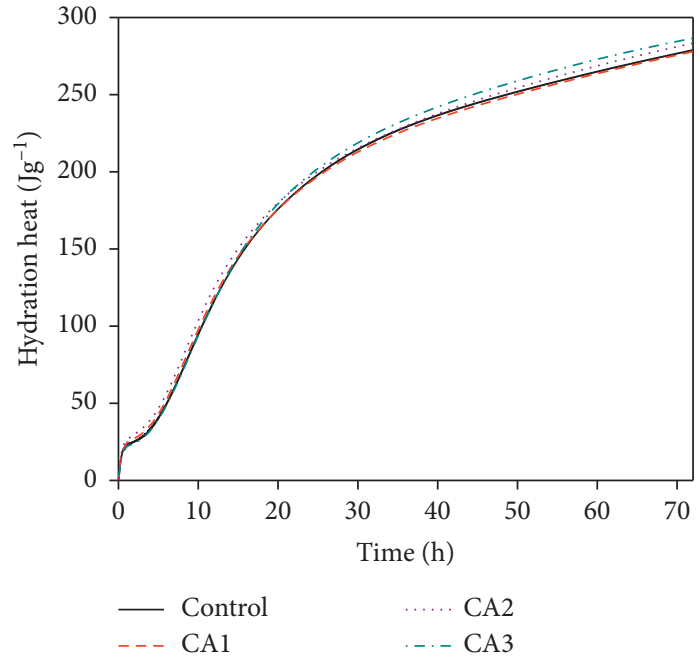

(b)

Figure 1: (a) Exothermic rates of hydration. (b) Cement samples' hydration heats.

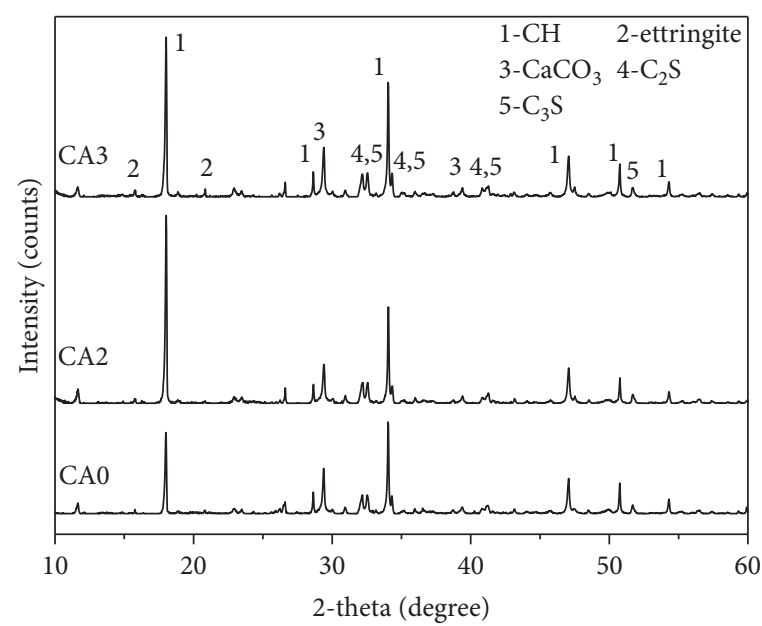

(a)

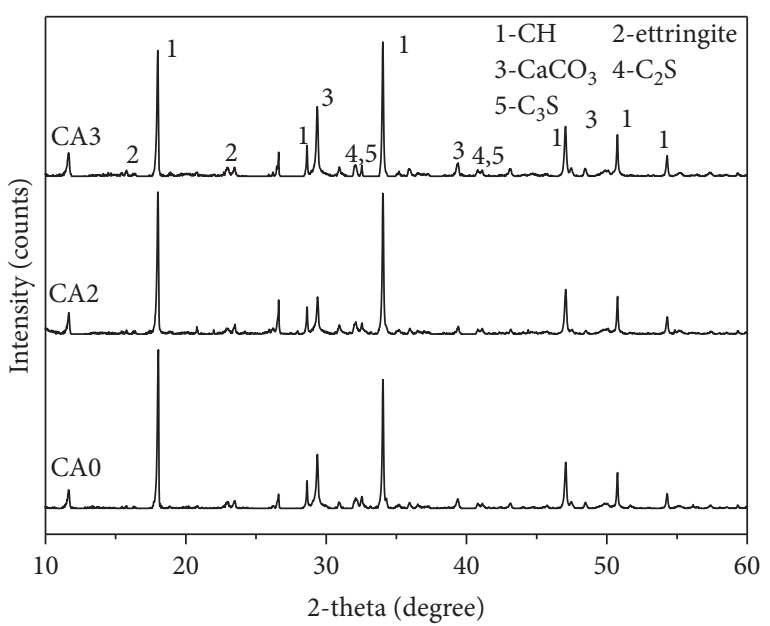

(b)

FIgURE 2: XRD patterns of the different samples after curing for (a) 3 days and (b) 28 days.

described in Section 2.2.3, their calculated weight loss and the $\mathrm{CH}$ content of the different groups are tabulated in Table 3.

Figure 3 and Table 3 suggest that, at the curing age of three days, the increase in the calcium acetate concentration reduced the weight loss in each temperature range and the $\mathrm{CH}$ content after an initial rise; CA2 reached the maximum weight loss and $\mathrm{CH}$ content, which implies that the calcium acetate at a $2 \%$ concentration expedited the cement hydration and accelerated the formation of AFm and $\mathrm{CH}$ within three days of curing, consistent with the results of the XRD analysis. After curing for 28 days, there is a similar trend in the variation of weight loss and $\mathrm{CH}$ content; however, the calcite weight loss of sample CA3 was larger compared to the other samples, which is due to the fact that more $\mathrm{Ca}^{2+}$ reacts with $\mathrm{CO}_{2}$. Thus, it can be deduced that calcium acetate could affect the cement hydration when increasing the curing age from 3 to 28 days and that calcium acetate at a $2 \%$ concentration would facilitate the cement hydration process.

The representative SEM images of groups CA0 and CA2 are represented in Figures 4(a) and 4(d) and Figures 4(b) and 4(d), respectively. The comparison between Figures 4(a) and 4(b) demonstrates that more needle-like ettringite is observed in the cement paste using $2 \%$ calcium acetate solution as the mixing liquid. Figures 4(c) and 4(d) reveal that more fixed $\mathrm{CH}$ crystals can be found in the specimen made of $2 \%$ calcium acetate solution; meanwhile, the microstructure of the specimen in group CA2 is denser than that of the specimen in group CA0. 
TABLE 3: The calculated weight loss and the $\mathrm{CH}$ content of the different groups in various temperature ranges.

\begin{tabular}{|c|c|c|c|c|c|}
\hline \multirow{3}{*}{ Groups } & \multicolumn{4}{|c|}{ Weight loss (\%) } & \multirow{3}{*}{$\mathrm{CH}$ content $(\%)$} \\
\hline & \multicolumn{4}{|c|}{ Temperature range } & \\
\hline & $80-120^{\circ} \mathrm{C}$ & $180-200^{\circ} \mathrm{C}$ & $400-500^{\circ} \mathrm{C}$ & $700-800^{\circ} \mathrm{C}$ & \\
\hline CA0 (3d) & 1.924 & 0.388 & 3.321 & 1.071 & 15.454 \\
\hline CA2 $(3 \mathrm{~d})$ & 2.011 & 0.424 & 3.398 & 1.148 & 15.900 \\
\hline CA3 $(3 \mathrm{~d})$ & 1.967 & 0.381 & 3.292 & 0.857 & 14.975 \\
\hline CA0 $(28 \mathrm{~d})$ & 2.450 & 0.578 & 3.870 & 1.356 & 18.190 \\
\hline CA2 $(28 \mathrm{~d})$ & 2.558 & 0.633 & 4.064 & 1.196 & 18.719 \\
\hline CA3 $(28 \mathrm{~d})$ & 2.505 & 0.626 & 3.595 & 1.821 & 17.842 \\
\hline
\end{tabular}

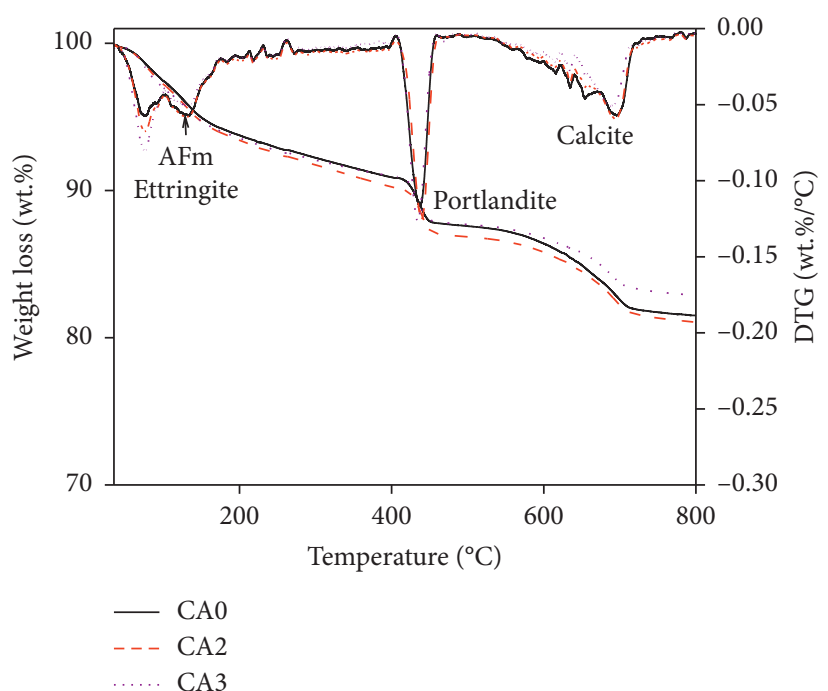

(a)

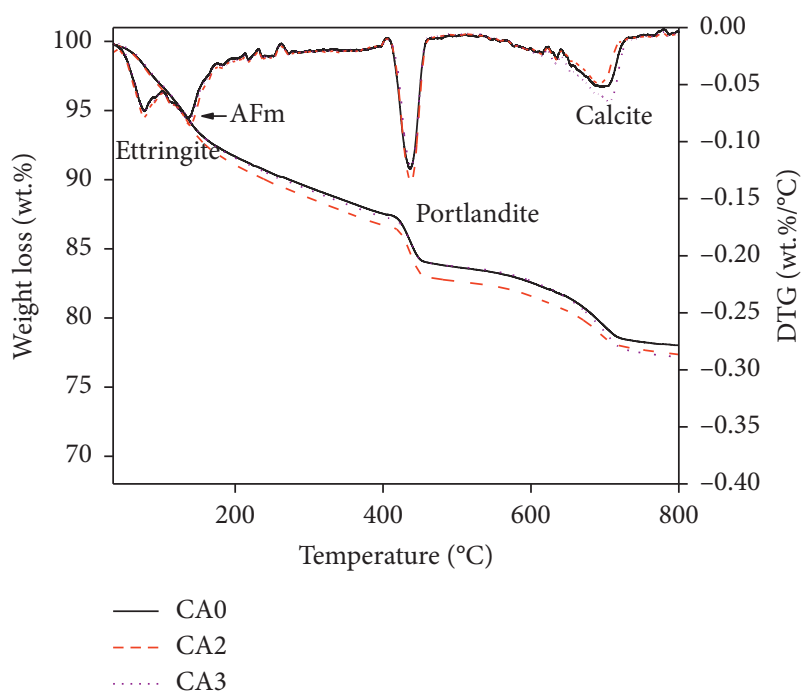

(b)

Figure 3: TGA results of the different groups after curing for (a) 3 days and (b) 28 days.

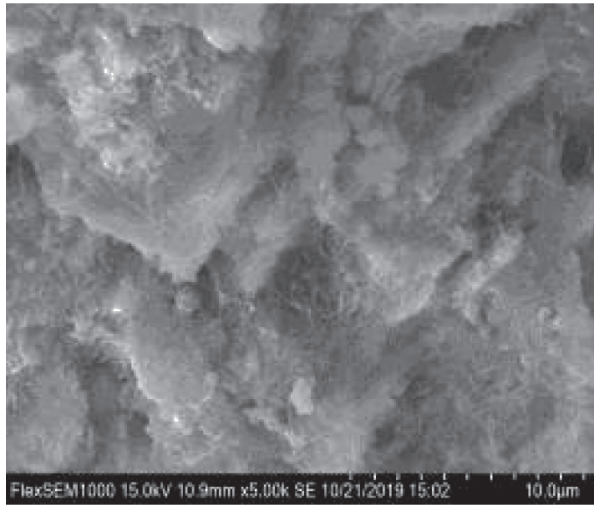

(a)

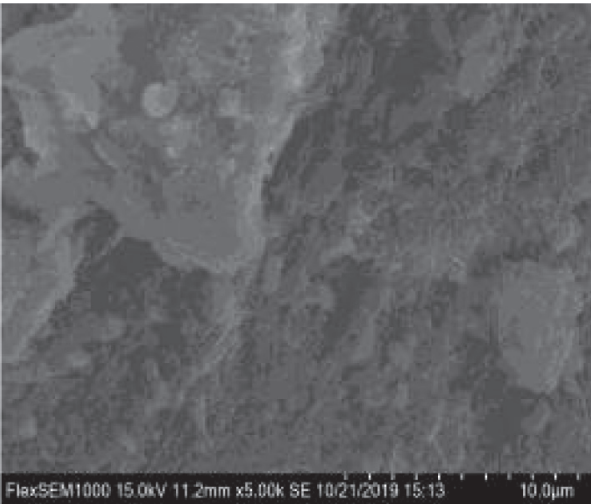

(b)

Figure 4: Continued. 


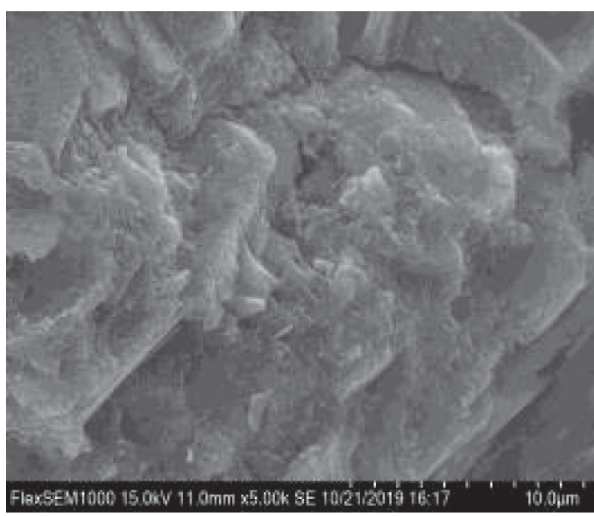

(c)

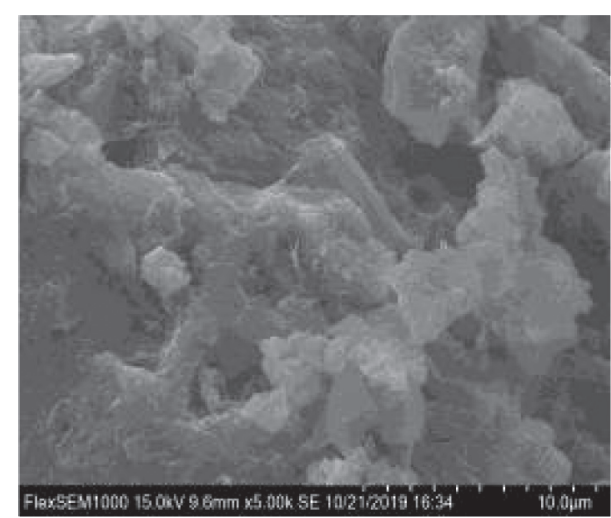

(d)

FIGURE 4: Representative SEM images of groups CA0 and CA2. (a) CA0 after curing for 3 days. (b) CA2 after curing for 3 days. (c) CA0 after curing for 28 days. (d) CA2 after curing for 28 days.

3.3. Workability. The flowability and setting time of the mortars with different concentrations of calcium acetate are presented in Figure 5 and 6 . As shown in Figure 5, the fluidity of the experimental groups increases slightly compared to that of the control group. It is possible that the extra calcium ions introduced by calcium acetate solutions are adsorbed on the surface of cement particles due to the calcium concentration gradient between cement particles and liquid, so that the cement particles are well dispersed due to mutual repulsion, causing the higher fluidity of fresh mortars.

Generally, the setting time of the mortars is associated with the hydration rate. As shown in Figure 6, the sequence of the setting time is $\mathrm{CA} 3>\mathrm{CA} 0>\mathrm{CA} 1>\mathrm{CA} 2$, which corresponds with the emergent time of the second exothermic peak that has been analysed in Section 3.1. The earlier the peak, the shorter the setting time. From the practical application point of view, the slight fluctuation of the setting time is acceptable.

3.4. Compressive Strength Analysis. The results of heat evolution and TGA/XRD analyses denote that the calcium acetate within an appropriate range of concentrations could meliorate the cement hydration, thereby enhancing the cement mortar's mechanical properties. Figure 7 depicts the impact of different concentrations of calcium acetate on the cement mortar's compressive strength. After curing for three days, the compressive strength of groups CA2 and CA3 is, respectively, 23.34 and $17.68 \%$ greater than that of group CA0, consistent with the calorimetry results in Section 3.1. After 28 days of curing, the compressive strength of group CA2 is $15.43 \%$ greater than that of group CA0, but that of group CA3 cannot reach the previous level, coherent with the TGA/XRD results. Moreover, the cement mortar's compressive strength in group CA1 is always close to that in group CA0 at the curing age of 3 and 28 days.

There are two main reasons for the above phenomenon. (1) Calcium acetate solution contains a large number of calcium ions and acetic acid radicals which can form a complex during the hydration process and can fill the

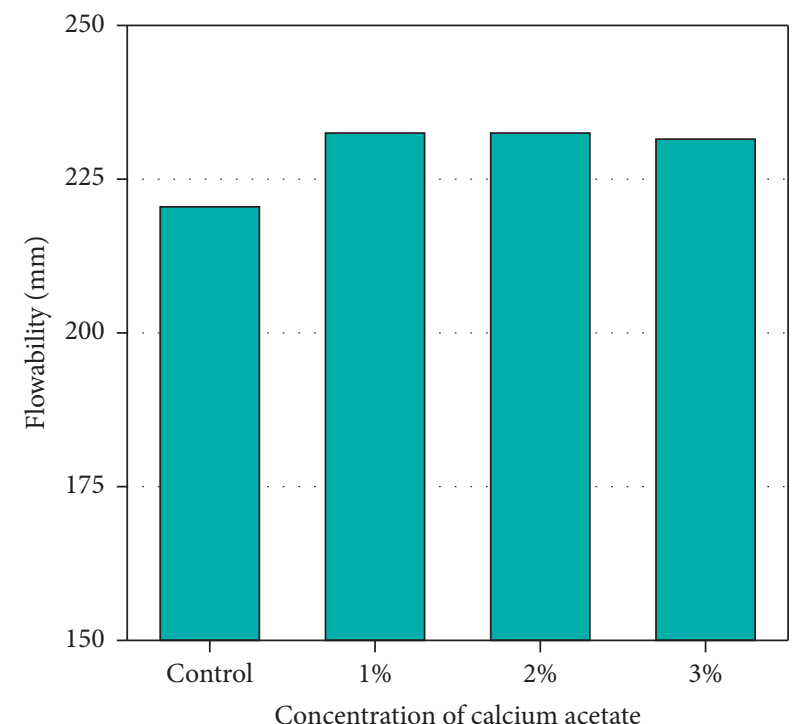

FIGURE 5: Effect of calcium acetate concentration on the flowability of mortar.

internal pores of the mortar specimen, thereby raising its compressive strength [35]. (2) The acidic environment affects the stability of hydration products, and low $\mathrm{pH}$ values have a negative impact on the mortar's strength development [36]. Therefore, when the acetic acid concentration of the base group increases in the solution, as in the case of using $3 \%$ calcium acetate solution, the solution $\mathrm{pH}$ drops, and the mortar's compressive strength begins to decline $[2,18]$.

3.5. MIP Test Results. Figure 8 depicts the evolution of the cumulative intrusion curves for all groups at $28 \mathrm{~d}$. It is clearly seen that CA2 samples show the lowest pore volume content among all the groups. This phenomenon can be attributed to the complex formed with calcium ions and acetic acid radicals, which could fill the internal pores of the mortars. And the fractions of total pore volume in each group are 


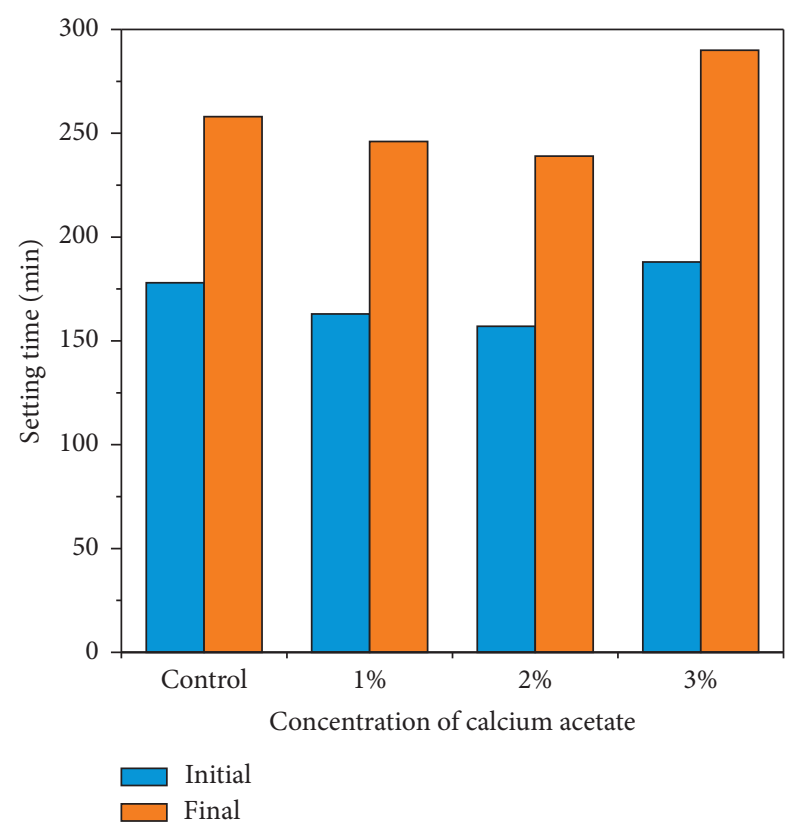

FIGURE 6: Effect of calcium acetate concentration on the setting time of mortar.

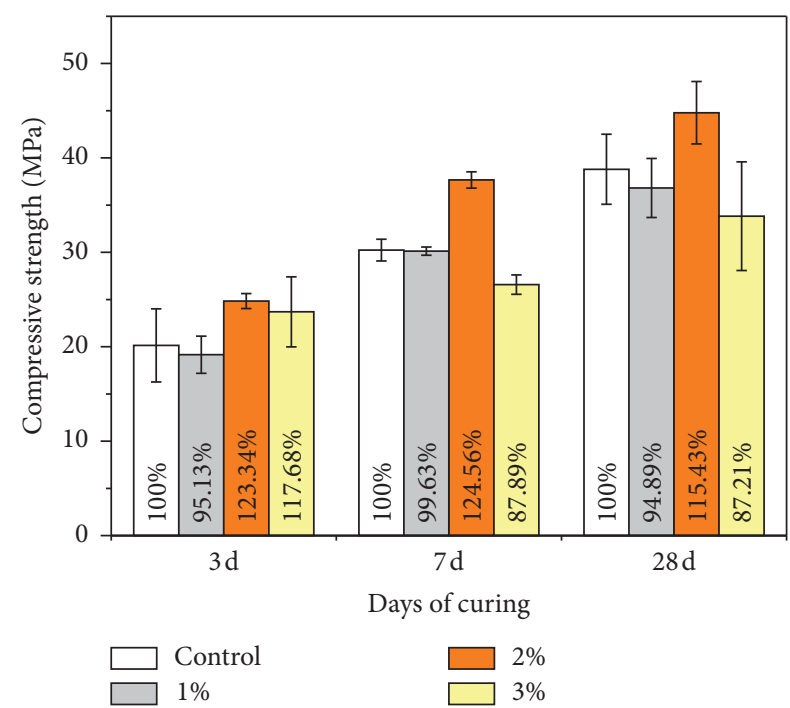

FIGURE 7: The cement mortar's compressive strength at different concentrations of calcium acetate.

shown in Figure 9. In sample CA2, the volume of pores in the size below $10 \mathrm{~nm}$ is maximum compared to the others. In cement-based materials, pores with a diameter less than $10 \mathrm{~nm}$ are usually known as gel pores and corresponding to the C-S-H gel formed during hydration [37], so the MIP test results in CA2 are consistent with the hydration product results. In addition, the volume of pores in the size between 100 and $10,000 \mathrm{~nm}$ in CA2 is the minimum among all groups. These indicate that the pore structure in sample CA2 is better than others, and the favorable pore structure can explain the highest compressive strength of CA2 in another way.

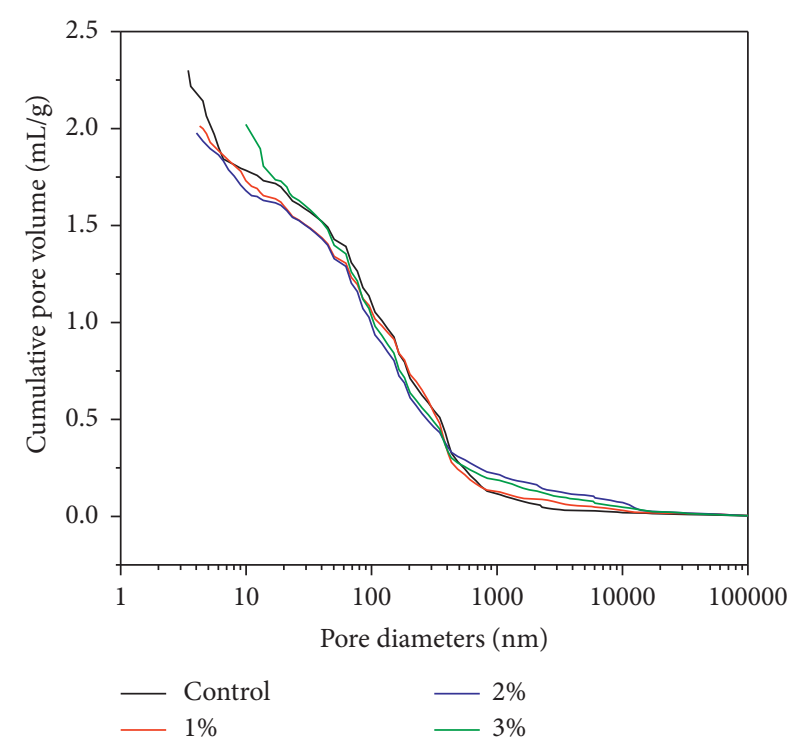

FIGURE 8: Relationship between the cumulative pore volume and the pore diameters.

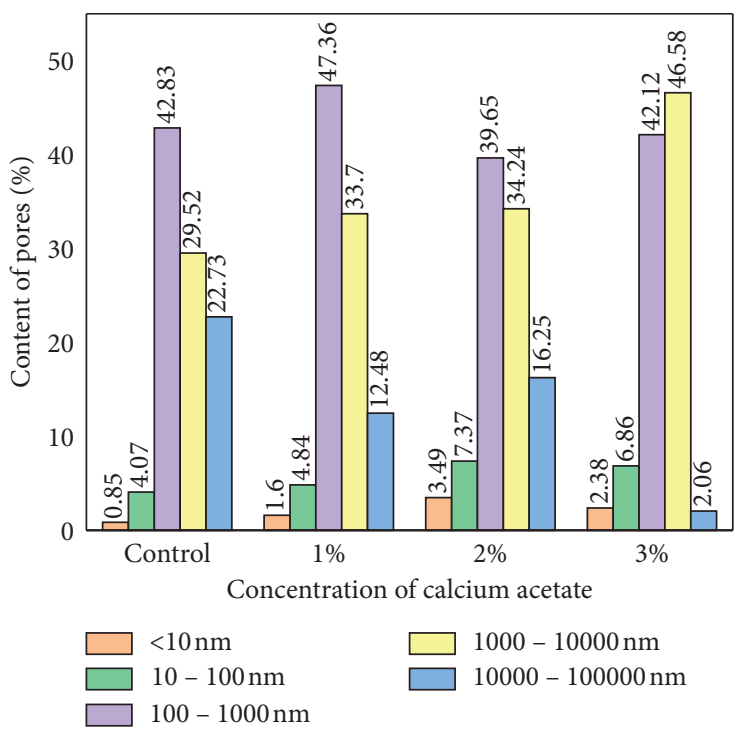

Figure 9: Content of pores in mortar samples.

\section{Conclusions}

The present work analysed the hydration evolution, hydration products, workability, compressive strength, and MIP tests of cement mortars prepared by various calcium acetate solutions as the mixing liquid.

The cement mortars prepared by $2 \%$ calcium acetate solution show higher and stronger peaks of $\mathrm{C}_{3} \mathrm{~S}$ and $\mathrm{C}_{3} \mathrm{~A}$. The heat release of the cement mortars containing 2 and $3 \%$ calcium acetate solutions is more than that of the others after curing for $72 \mathrm{~h}$. Correlatively, the setting time of the mortars is decided by the emergent time of the second exothermic peak. The TGA/XRD results and SEM images indicate that 
the calcium acetate solution at a concentration of $2 \%$ could expedite the cement hydration process and produce more $\mathrm{AFm}$ and $\mathrm{CH}$ crystals. And incorporating calcium acetate will increase the flowability of cement mortars slightly. The use of calcium acetate solution at a concentration of $2 \%$ can raise the compressive strength of the mortars up to 23.34 and $15.43 \%$ higher than the control group when curing for 3 and 28 days, respectively. Meanwhile, the MIP test results also indicate that this group has the lowest porosity among all groups due to the complex formed with calcium ions and acetic acid radicals, which could fill the internal pores of the mortars.

This work confirms that the residual products of RCAs which are modified by acetate acid have the positive effect on cement mortars. We further studied the effect of calcium acetate on cement hydration and compressive strength of concrete. It also provides experimental data for exploring the effect of calcium ions on cement-based materials in acidulous environment. This is helpful to better understand the role of calcium acetate in the hydration and hardening process of cement. It should also be noted that this study only focuses on the impact of calcium acetate solution on the cement mortar's compressive strength, and the durability and shrinkage characteristics of the mortars will be reported in another study in the follow-up work.

\section{Data Availability}

The data used to support the findings of this study are available from the corresponding author upon request.

\section{Conflicts of Interest}

The authors declare that there are no conflicts of interest regarding the publication of this paper.

\section{Acknowledgments}

This work was supported by the Natural Science Foundation of Universities in Anhui Province (Grant no. KJ2019A0129), the Key Research and Development Project of Anhui Province (Grant no. 201904a07020081), the Natural Science Foundation of Anhui Province (Grant no. 2008085QE244), the Chinese Postdoctoral Science Foundation (Grant no. 2020M681988), Innovation Foundation for Postgraduates of Anhui University of Science and Technology (Grant no. 2019CX2014), and the Research Foundation for Young Teachers of Anhui University of Science and Technology (Grant no. QN2018105).

\section{References}

[1] W. Y. Tam Vivian, A. C. J. Evangelista, and A. C. Jorge Evangelista, "A review of recycled aggregate in concrete applications (2000-2017)," Construction and Building Materials, vol. 172, pp. 272-292, 2018.

[2] Z. Pan, S. Wang, Y. Liu et al., "The hydration, pore structure and strength of cement-based material prepared with waste soaking solution from acetic acid treatment of regenerated aggregates," Journal of Cleaner Production, vol. 235, pp. 866-874, 2019.

[3] M. Behera, S. K. Bhattacharyya, A. K. Minocha, R. Deoliya, and S. Maiti, "Recycled aggregate from C\&D waste \& its use in concrete - a breakthrough towards sustainability in construction sector: a review," Construction and Building Materials, vol. 68, pp. 501-516, 2014.

[4] N. D. Oikonomou, "Recycled concrete aggregates," Cement and Concrete Composites, vol. 27, no. 2, pp. 315-318, 2005.

[5] Productivity Commission, Waste Management: Productivity Commission Draft Report, Australian Government, Canberra, Australia, 2006.

[6] C. Liang, B. Pan, Z. Ma, Z. He, and Z. Duan, "Utilization of $\mathrm{CO}_{2}$ curing to enhance the properties of recycled aggregate and prepared concrete: a review," Cement and Concrete Composites, vol. 105, Article ID 103446, 2019.

[7] R. S. Ravindrajah, Y. H. Loo, and C. T. Tam, "Strength evaluation of recycled-aggregate concrete byin-situ tests," Materials and Structures, vol. 21, no. 4, pp. 289-295, 1988.

[8] S. M. Levy and P. Helene, "Durability of recycled aggregates concrete: a safe way to sustainable development," Cement and Concrete Research, vol. 34, no. 11, pp. 1975-1980, 2004.

[9] A. Domingo-Cabo, C. Lázaro, F. López-Gayarre, M. A. Serrano-López, P. Serna, and J. O. Castaño-Tabares, "Creep and shrinkage of recycled aggregate concrete," Construction and Building Materials, vol. 23, no. 7, pp. 2545-2553, 2009.

[10] C. Shi, Y. Li, J. Zhang, W. Li, L. Chong, and Z. Xie, "Performance enhancement of recycled concrete aggregate-a review," Journal of Cleaner Production, vol. 112, pp. 466-472, 2016.

[11] S. C. Kou and C. S. Poon, "Enhancing the durability properties of concrete prepared with coarse recycled aggregate," Construction and Building Materials, vol. 35, no. 10, pp. 69-76, 2012.

[12] S.-C. Kou and C.-S. Poon, "Properties of concrete prepared with PVA-impregnated recycled concrete aggregates," $\mathrm{Ce}$ ment and Concrete Composites, vol. 32, no. 8, pp. 649-654, 2010.

[13] N. K. Dhami, M. S. Reddy, and A. Mukherjee, "Biomineralization of calcium carbonates and their engineered applications: a review," Frontiers in Microbiology, vol. 4, no. $314,2013$.

[14] L. Li, J. Xiao, and C. S. Poon, "Dynamic compressive behavior of recycled aggregate concrete," Materials and Structures, vol. 49, no. 11, pp. 4451-4462, 2016.

[15] E. Mulder, T. P. R. de Jong, L. Feenstra, and F.. A. Lourens, "Closed Cycle Construction: an integrated process for the separation and reuse of C\&D waste," Waste Management, vol. 27, no. 10, pp. 1408-1415, 2007.

[16] V. W. Y. Tam, C. M. Tam, and K. N. Le, "Removal of cement mortar remains from recycled aggregate using pre-soaking approaches," Resources, Conservation and Recycling, vol. 50, no. 1, pp. 82-101, 2007.

[17] S. Ismail and M. Ramli, "Engineering properties of treated recycled concrete aggregate (RCA) for structural applications," Construction and Building Materials, vol. 44, pp. 464-476, 2013.

[18] L. Wang, J. Wang, X. Qian, P. Chen, Y. Xu, and J. Guo, “An environmentally friendly method to improve the quality of recycled concrete aggregates," Construction and Building Materials, vol. 144, pp. 432-441, 2017.

[19] F. Messina, C. Ferone, F. Colangelo, and R. Cioffi, "Low temperature alkaline activation of weathered fly ash: influence 
of mineral admixtures on early age performance," Construction and Building Materials, vol. 86, pp. 169-177, 2015.

[20] A. S. Al-Harthy, R. Taha, J. Abu-Ashour, K. Al-Jabri, and S. Al-Oraimi, "Effect of water quality on the strength of flowable fill mixtures," Cement and Concrete Composites, vol. 27, no. 1, pp. 33-39, 2005.

[21] Z. Shi, Z. Shui, Q. Li, and H. Geng, "Combined effect of metakaolin and sea water on performance and microstructures of concrete," Construction and Building Materials, vol. 74, pp. 57-64, 2015.

[22] B. Çomak, "Effects of use of alkaline mixing waters on engineering properties of cement mortars," European Journal of Environmental and Civil Engineering, vol. 22, no. 6, pp. 736-754, 2018.

[23] E. Arunakanthi, H. S. Rao, and I. R. Reddy, "Effects of hydrochloric acid in mixing and curing water on strength of high-performance metakaolin concrete," International Journal of Applied Engineering and Technology, vol. 2, no. 2, pp. 68-76, 2012.

[24] X. Kong, S. Emmerling, J. Pakusch, M. Rueckel, and J. Nieberle, "Retardation effect of styrene-acrylate copolymer latexes on cement hydration," Cement and Concrete Research, vol. 75, pp. 23-41, 2015.

[25] F. Zou, B. Ma, T. Zhang et al., "Effect of triisopropanolamineon compressive strength and hydration of cement-fly ash paste," Construction and Building Materials, vol. 179, pp. 89-99, 2018.

[26] J. Yang, J. Huang, Y. Su et al., "Eco-friendly treatment of lowcalcium coal fly ash for high pozzolanic reactivity: a step towards waste utilization in sustainable building material," Journal of Cleaner Production, vol. 238, p. 117962, 2019.

[27] J. Mei, H. Tan, H. Li et al., "Effect of sodium sulfate and nano$\mathrm{SiO} 2$ on hydration and microstructure of cementitious materials containing high volume fly ash under steam curing," Construction and Building Materials, vol. 163, pp. 812-825, 2018.

[28] ASTM, Standard Test Method for Flow of Hydraulic Cement Mortar ASTM C1437-15, ASTM International, West Conshohocken, PA, USA, 2015.

[29] GB/T, Test Methods for Water Requirement of Normal Consistency, Setting Time and Soundness of the Portland Cement GB/T 1346-2011, China National Standardization Management Committee, Beijing, China, 2011.

[30] ASTM, Standard Test Method for Compressive Strength of Hydraulic Cement Mortars (Using 2-in or [50-mm] Cube Specimens) ASTM C109, ASTM International, West Conshohocken, PA, USA, 2010.

[31] P. H. R. Borges, J. O. Costa, N. B. Milestone, C. J. Lynsdale, and R. E. Streatfield, "Carbonation of $\mathrm{CH}$ and C-S-H in composite cement pastes containing high amounts of BFS," Cement and Concrete Research, vol. 40, no. 2, pp. 284-292, 2010.

[32] A. Bakolas, E. Aggelakopoulou, A. Moropoulou, and S. Anagnostopoulou, "Evaluation of pozzolanic activity and physicomechanical characteristics in metakaolin-lime pastes," Journal of Thermal Analysis and Calorimetry, vol. 84, no. 1, pp. 157-163, 2006.

[33] F. S. Hashem, M. S. Amin, and S. M. A. El-Gamal, "Improvement of acid resistance of Portland cement pastes using rice husk ash and cement kiln dust as additives," Journal of Thermal Analysis and Calorimetry, vol. 111, no. 2, pp. 13911398, 2013.

[34] H. Park, Y. Jeong, J.H. Jeong, and J.E. Oh, "Strength development and hydration behavior of self-activation of commercial ground granulated blast-furnace slag mixed with purified water," Materials, vol. 9, no. 3, 2016.

[35] D. D. Nguyen, L. P. Devlin, P. Koshy, and C. C. Sorrell, "Effects of acetic acid on early hydration of portland cement," Journal of Thermal Analysis and Calorimetry, vol. 123, no. 1, pp. 489-499, 2015.

[36] J. W. Bullard, H. M. Jennings, R. A. Livingston et al., "Mechanisms of cement hydration," Cement and Concrete Research, vol. 41, no. 12, pp. 1208-1223, 2011.

[37] A. M. Gajewicz-Jaromin, P. J. McDonald, A. C. A. Muller, and K. L. Scrivener, "Influence of curing temperature on cement paste microstructure measured by $1 \mathrm{H}$ NMR relaxometry," Cement and Concrete Research, vol. 122, pp. 147-156, 2019. 